\title{
Unsteady Flow Condition between Front and Rear Rotor of Contra-Rotating Small Sized Axial Fan
}

\author{
Toru Shigemitsu' ${ }^{1}$, Hiroaki Fukuda², Katsuhiko Hirosawa ${ }^{2}$ \\ ${ }^{1}$ Institute of Science and Technology, Tokushima University, Tokushima, Japan \\ ${ }^{2}$ Graduate School of Advanced Technology and Science, Tokushima University, Tokushima, Japan \\ Email: t-shige@tokushima-u.ac.jp
}

How to cite this paper: Shigemitsu, T., Fukuda, H. and Hirosawa, K. (2017) Unsteady Flow Condition between Front and Rear Rotor of Contra-Rotating Small Sized Axial Fan. Open Journal of Fluid Dynamics, 7, 371-385.

https://doi.org/10.4236/ojfd.2017.73025

Received: July 29, 2017

Accepted: September 23, 2017

Published: September 26, 2017

Copyright $\odot 2017$ by authors and Scientific Research Publishing Inc. This work is licensed under the Creative Commons Attribution International License (CC BY 4.0).

http://creativecommons.org/licenses/by/4.0/

\begin{abstract}
Contra-rotating small-sized axial fans are used as cooling fans for electric equipment. In the case of the contra-rotating rotors, the blade row distance between front and rear rotors is a key parameter for the performance and stable operation. The wake and potential interference occur between the front and rear rotors and leakage flow from the front rotor tip influences on the flow condition of the rear rotor near the shroud when the blade row distance is small. Therefore, it is important to clarify the flow condition between front and rear rotors. The fan static pressure curves were obtained by the experimental apparatus and the numerical analysis was also conducted to investigate the internal flow between front and rear rotors. The leakage flow from the front rotor tip reaches the leading edge of the rear rotor when the blade row distance is small as $L=10 \mathrm{~mm}$ and the pressure fluctuations at the leading edge of the rear rotor tip becomes larger than those at other radial positions. In the present paper, the vorticity contour between front and rear rotors is shown and pressure fluctuations related to the leakage flow from the front rotor is investigated using the numerical analysis result. Then, suitable blade row distance for the contra-rotating small sized axial fan is discussed based on the internal flow condition.
\end{abstract}

\section{Keywords}

Turbomachinery, Contra-Rotating Axial Flow Fan, Leakage Flow, Wake

\section{Introduction}

Power consumption has been increasing significantly in data centers, IT devices and machines because of spread of cloud computing, establishment of ubiquit- 
ous networking society and increase in rate of electric parts in machines [1]. From the viewpoint of the global warming and energy savings, there is a strong demand for the reduction of power consumption in above facilities and equipment. The electrical power used for the cooling of the IT devices for data centers is huge the same as the electric power used for the IT devices itself. Small-sized axial fans are used as air coolers for electric equipment, i.e. laptop, desk top computers and servers. There is a strong demand for high pressure and large flow rate of fans according to the increase of quantity of heat from electric devices. However, the increase of the pressure and flow rate by the increase of the fan diameter is restricted because of the limitation of the space. Therefore, high rotational speed design is implemented, although, it causes the deterioration of the efficiency and increase of the noise. On the other hand, lower rotational speed design [2] and advantages on the performance of the contra-rotating fans and pumps were verified by experimental results [3] [4]. Then, the adoption of the contra-rotating rotors for the small-sized axial fans was proposed for the improvement of the performance. In the case of contra-rotating rotors, the axial space becomes larger than conventional small-sized axial fans. However, it is adequate choice to apply the contra-rotating rotors for small-sized fan because the axial space can be ensured in electrical devices as compared to that of the radial space.

In the case of the contra-rotating rotors, it is necessary to design the rear rotor considering the unsteady circumferential velocity distributions at the outlet of the front rotor [5]. Further, the fan noise becomes larger than the conventional rotor stator type fan because of the interaction between the front and rear rotors. Then, the passive noise reductions with the perforated blade were proposed for the contra-rotating fan [6]. It is important to clarify the influence of the wake from the front rotor to the rear rotor and the potential interaction between the front and rear rotors to increase the performance and to reduce the fan noise [7]. The blade row distance between the front and rear rotors is a key parameter to consider the wake and potential interaction for the contra-rotating fan. The influence of the blade row distance between the front and rear rotors and pressure fluctuations on the casing wall were investigated for the counter rotating fan with fan diameter $D=375 \mathrm{~mm}$ [4] [8]. On the other hand, the conventional design method and the theory for the turbomachinery should be modified for small-sized axial fans because small-sized axial fans applied to electrical devices belong to extremely small size field in the turbomachinery [9]. Therefore, there is the strong demand to establish the design method for small-sized axial fans based on the internal flow between the front and rear rotors.

In the present paper, the performance curves of the contra-rotating small-sized axial fan with $100 \mathrm{~mm}$ diameter are compared with the unsteady numerical analysis results to verify the validity of the unsteady numerical analysis results. Then, the pressure fluctuations are investigated by the numerical analysis. After that, the vorticity contour between front and rear rotors is shown and pressure fluctuations related to the leakage flow from the front rotor is clarified using the 
numerical analysis result. Finally, the suitable blade row distance for the contra-rotating small sized axial fan is discussed based on the internal flow condition.

\section{Experimental Apparatus and Method}

The geometry of the rotor and primary dimensions of the contra-rotating small-sized axial fan (RRtype) are shown in Figure 1 and Table 1, respectively. The hub tip ratio was $D_{h} / D_{t}=45 \mathrm{~mm} / 98 \mathrm{~mm}$, tip clearance was $c=1 \mathrm{~mm}$ and the design flow rate was $Q_{d}=0.016 \mathrm{~m}^{3} / \mathrm{s}$. Fan static pressure at the design point was $P_{d R R}=14.7 \mathrm{~Pa}$ for RRtype with the same fan static pressure of each front and rear rotor. The rotational speed of front and rear rotors of RRtype was $N_{f}=N_{r}=$ $1780 \mathrm{~min}^{-1}$. This fan was designed with the free vortex design. In this research, an aerofoil blade was used because there was a report that mentioned an advantage of the airfoil blade for the small-sized axial fan [10], however, a circular-arc blade was generally used for small-sized axial fans. Figure 2 shows the schematic diagram of the experimental apparatus for RRtype. The experimental apparatus was designed based on the Japanese Industrial Standard and the air blown in the test section passed the rotor, chamber, measurement duct and booster fan and blew out in the ambient atmosphere. The fan static pressure $\left(P_{s}\right)$ was measured by the pressure difference between static holes downstream of the rotor installed at the chamber and ambient air. Further, the rotational speed was controlled by the servo motor and the flow rates were measured by an orifice meter set at the measurement duct. The pressure curves of RRtype from the cutoff flow rate to

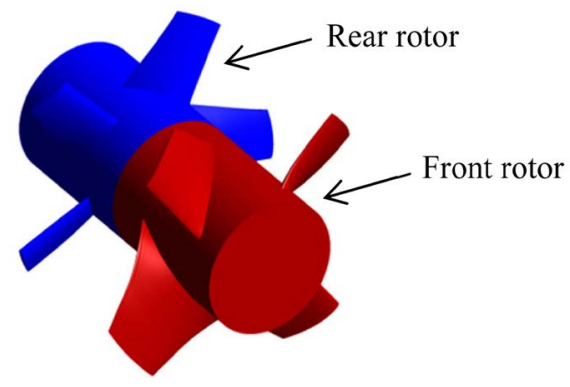

Figure 1. Contra-rotating small-sized axial fan (RRtype).

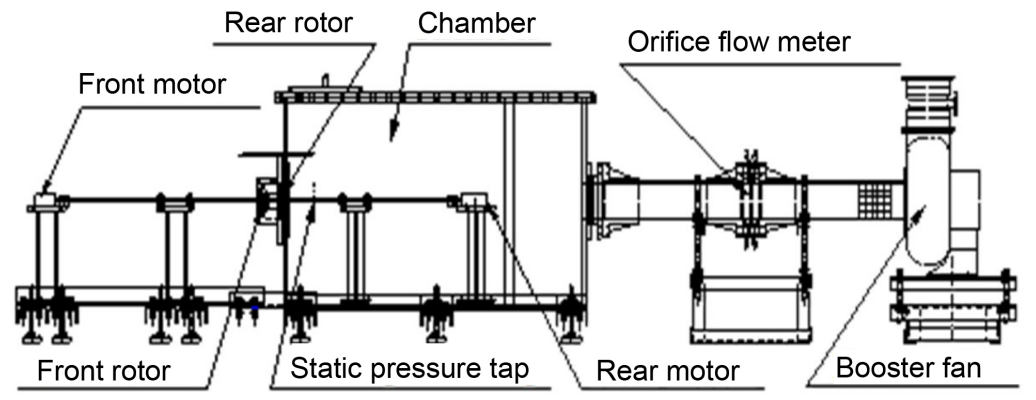

Figure 2. Experimental apparatus. 
Table 1. Primary dimensions of RRtype.

\begin{tabular}{ccccc}
\hline & & Hub & Mid & Tip \\
\hline \multirow{5}{*}{ Front rotor } & Diameter [mm] & 45 & 72 & 98 \\
& Blade number & & 4 & \\
& Blade profile & & NACA4409 & \\
& Solidity & 1.196 & 0.496 & 0.290 \\
& Stagger angle & $44.7^{\circ}$ & $61.1^{\circ}$ & $68.2^{\circ}$ \\
& Blade number & & 5 & \\
& Blade profile & & NACA4412 & \\
& Solidity & 0.910 & 0.447 & 0.288 \\
& Stagger angle & $56.7^{\circ}$ & $64.5^{\circ}$ & $69.6^{\circ}$ \\
\hline
\end{tabular}

large flow rate were investigated in the experiment with the constant rotational speed $N_{f}=N_{r}=1780 \mathrm{~min}^{-1}$. In this research, the performance test was conducted with two different blade row distances $L=10 \mathrm{~mm}$ (non-dimensional axial distance divided by front rotor tip chord length $\left.L / I_{F R}=0.42\right), 30 \mathrm{~mm}\left(L / I_{F R}=1.27\right)$. $L$ was defined as the axial distance from the trailing edge of the front rotor to the leading edge of the rear rotor at the hub.

\section{Numerical Analysis Conditions}

The commercial software ANSYS-CFX 14.5 was used to investigate the flow condition between the front and rear rotors of the contra-rotating small-sized axial fan which couldn't be measured by the experiment. In the numerical analysis, the numerical model which was almost the same with the experimental apparatus was used. The unsteady numerical analysis was conducted using the three dimensional model. The numerical analysis grids used for the numerical analysis are shown in Figure 3. To simplify the numerical analysis, the servo motors and the shafts of the servo motors are removed in the numerical analysis model. The numerical domains comprised the inlet, rotor, chamber and outlet duct regions. The numerical grid elements were 617,090 for the inlet region, $1,479,336$ for the chamber region and 237,628 for the outlet duct region. The numerical grid elements for the rotor region were 5,542,038 for $L=10 \mathrm{~mm}$ and $6,038,826$ for $L=30 \mathrm{~mm}$. The tip clearance kept $1 \mathrm{~mm}$ as the same with the experimental apparatus in the numerical analysis and the number of elements from the blade tip to the casing was 7. At the inlet boundary, the uniform velocity was given and the constant pressure was given at the outlet boundary condition. Each front and rear rotor region was simulated on the relative reference frame considering the rotation of each rotor. Non-slip wall condition was used for the shroud and hub surfaces. In the rotational regions, the shroud was set to rotate in the opposite direction of the rotor to make the shroud stationary in the absolute coordinate system. The coupling between the front and rear rotors was conducted by the sliding mesh (Transient Rotor Stator Model). SST (Shear Stress Transport) turbulence model suitable for the estimation of the separation was 


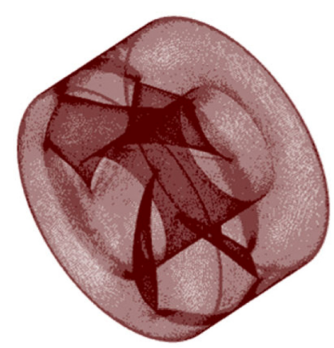

(a) Front rotor

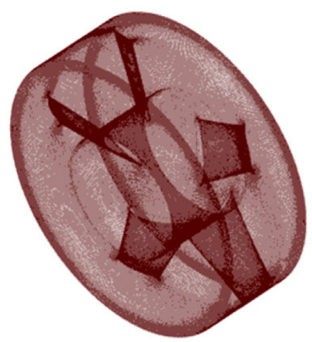

(b) Rear rotor

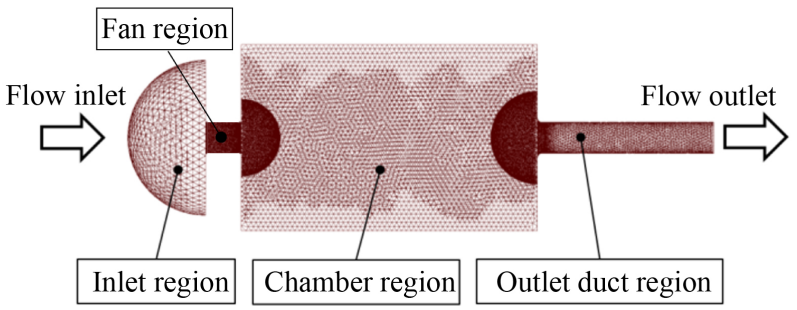

(c) Whole domains

Figure 3. Numerical analysis grids.

used because the test fan having the complex flow with the separation near the wall. "Automatic" near wall treatment recommended for the SST model was used to allow for a smooth shift from a low-Reynolds number form to a wall function formulation. The unsteady numerical analysis was conducted at six flow rates $\left(0.01 Q_{\phi} 0.1 Q_{\phi} 0.6 Q_{\phi} 0.9 Q_{\phi} 1.0 Q_{d}\right.$ and $\left.1.2 Q_{d}\right)$. The time step number per one rotor rotation was 180 and the time step was $\Delta t=1.8727 \times 10^{-4} \mathrm{~s}$ (corresponding $2^{\circ}$ of the rotor rotation). The data of one rotor rotation were obtained after 6 rotor rotations in unsteady numerical analysis. The convergence criteria at each time step were set as the residual less than $1.0 \times 10^{-4}$. The computational time for the unsteady numerical analysis was $10-14$ days depending on the flow rate.

\section{Experimental and Numerical Analysis Results}

\subsection{Performance Curve of $L=10 \mathrm{~mm}$ and $L=30 \mathrm{~mm}$}

The fan static pressure curves of RRtype at each blade row distance ( $L=10,30$ $\mathrm{mm}$ ) are shown in Figure 4. In Figure 4, the fan static pressure obtained by both experiment and numerical analysis are shown. In the unsteady numerical analysis, the fan static pressure was obtained at the same point in the experiment and 180 static pressure data of one rotor rotation were averaged. The vertical axis and horizontal axis in Figure 4 show the fan static pressure $P_{s}$ and flow rate $Q$. It was found from Figure 4 that fan static pressure of RRtype linearly increased as the flow rate decreased, and the pressure curve of RRtype showed the stable negative curve. The difference of the fan static pressure between $L=10 \mathrm{~mm}$ and $L=$ $30 \mathrm{~mm}$ was $P_{s}=0.02 \mathrm{~Pa}$ (Exp.) at the design flow rate $Q_{d}=0.016 \mathrm{~m}^{3} / \mathrm{s}$. The influence of the blade row distance in the range of $L=10-30 \mathrm{~mm}$ on the fan static pressure was small. The numerical analysis results could predict the experimental results accurately and capture the tendency of the performance curves of the 


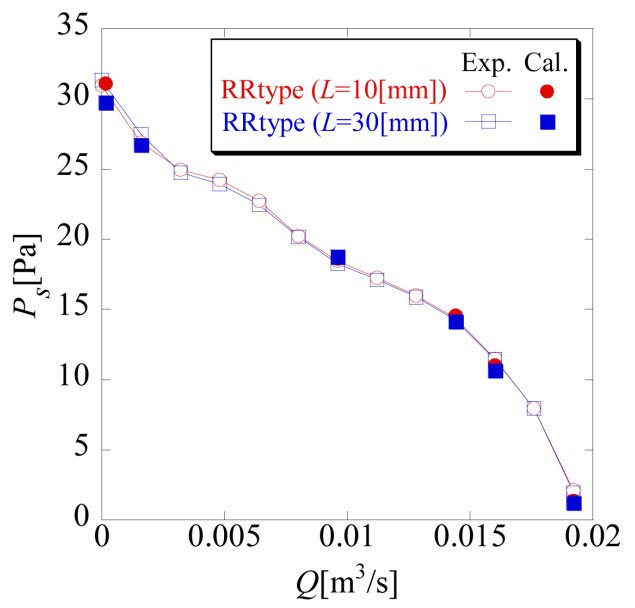

Figure 4. Fan static pressure of RRtype.

experimental results. It was difficult to measure the efficiency of this small fan. Therefore, the efficiency of the test fan was investigated by the numerical analysis results. The static pressure efficiency of RRtype for $L=10 \mathrm{~mm}$ and $30 \mathrm{~mm}$ is shown in Figure 5. The maximum static pressure efficiency was $\eta=58.0 \%$ for $L=$ $10 \mathrm{~mm}$ and $\eta=57.0 \%$ for $L=30 \mathrm{~mm}$ and the difference of the efficiency for $L=$ $10 \mathrm{~mm}$ and $30 \mathrm{~mm}$ were also small in wide flow rate range. It was found from these results in Figure 4 and Figure 5 that the performance of the test fan kept almost constant by the blade row distance $L=30 \mathrm{~mm}\left(L / I_{F R}=1.27\right)$ [11].

\subsection{Unsteady Flow Condition between Front and Rear Rotors $(L=10,30 \mathrm{~mm})$}

In this section, the pressure fluctuations around the rotor phase locked each front and rear rotor's rotations are shown and the unsteady flow condition associated with the wake, potential interference and leakage flow from the blade tip clearance are discussed by the unsteady numerical analysis results. The sampling points for pressure fluctuations and definition of the relative position of the front and rear rotors are shown in Figure 6. The pressure fluctuations for the front rotor were obtained $0.1 \mathrm{~mm}$ downstream from the trailing edge (TE) of the front rotor. And the data for the rear rotor were obtained $0.1 \mathrm{~mm}$ upstream from the leading edge (LE) of the rear rotor. The rotational angles of the front and rear rotors are shown as $\theta_{f} \theta_{r}$ respectively. The rotational angles are defined as the angles of the $25 \%$ chord length position of each front and rear rotor from the arbitrary meridional plane. The relative angle of the front and rear rotors $\theta_{f r}$ are defined as $\theta_{f r}=\theta_{f}+\theta_{r}$, the initial relative angle is $\theta_{f r}=0^{\circ}\left(\theta_{f}=\theta_{r}=0^{\circ}\right)$. The rotational direction of the angle $\theta_{f} \theta_{r}$ are the same with the rotational direction of the front and rear rotors respectively.

The pressure fluctuations at the TE of the front rotor at the design flow rate $Q_{d}=0.016 \mathrm{~m}^{3} / \mathrm{s}$ obtained by the numerical analysis is shown in Figure 7 . The vertical axis is the fluctuations of the static pressure $\Delta P_{s}$ from the averaged value and the horizontal axis is the relative angle of the front and rear rotors $\theta_{f r}$. Further, 


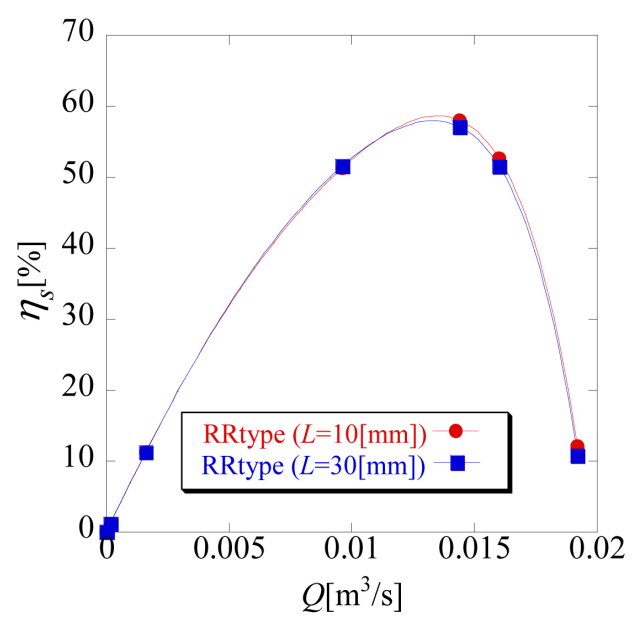

Figure 5. Fan static pressure efficiency of RRtype.

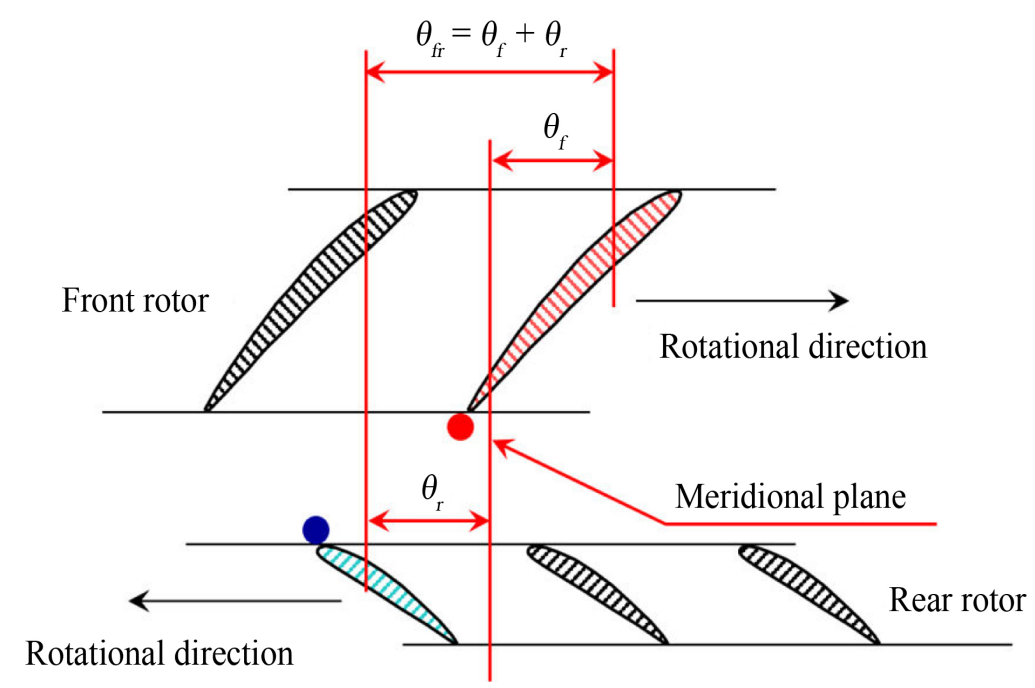

Figure 6. Sampling points and relative position of front and rear rotors.

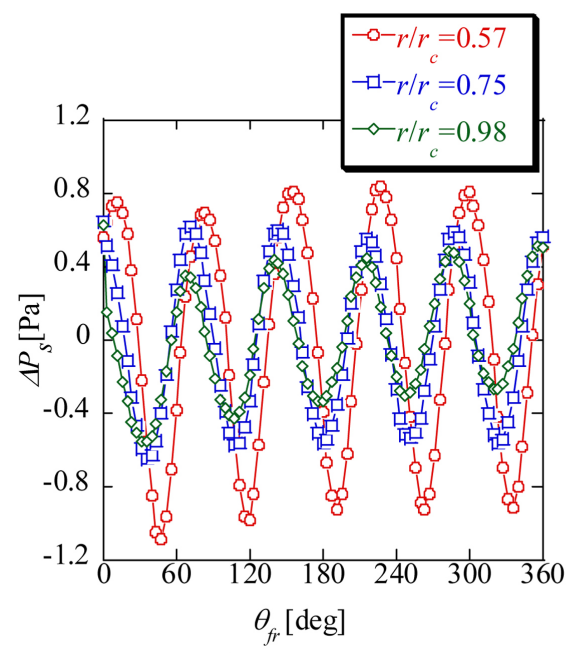

(a) $L=10 \mathrm{~mm}$

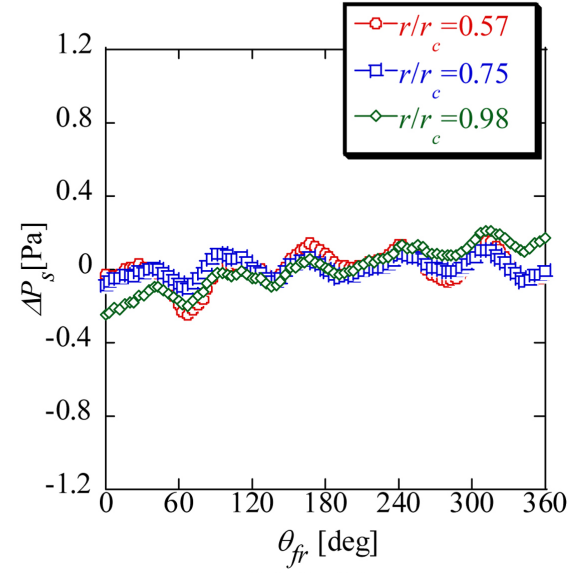

(b) $L=30 \mathrm{~mm}$

Figure 7. Pressure fluctuations at TE of front rotor. 
$r / r_{c}$ shows non-dimensional radius divided by the radius at the casing; $r / r_{c}=0.45$ and $r / r_{c}=1.0$ correspond the hub and casing. Because the pressure in Figure 7 was phase locked the front rotor rotation, the potential interference from the rear rotor became clear if the unsteady pressure fluctuations from the front rotor were small. The periodic fluctuations with five peaks corresponding to the rear rotor blade number $Z_{R}=5$ were generated for the blade row distance $L=10 \mathrm{~mm}$ and $L=30 \mathrm{~mm}$ in Figure 7. The pressure fluctuations $\Delta P_{s}$ at the TE of front rotor were within $\pm 1.2 \mathrm{~Pa}$ for $L=10 \mathrm{~mm}$ (fan static pressure $P_{s}=11.47 \mathrm{~Pa}$ at $Q_{d}$ for $L=10 \mathrm{~mm}$ ) and $\pm 0.3 \mathrm{~Pa}$ for $L=30 \mathrm{~mm}$ (fan static pressure $P_{s}=11.45 \mathrm{~Pa}$ at $Q_{d}$ for $L=30 \mathrm{~mm}$ ) respectively. The pressure fluctuations became small as the distance from the rear rotor increased and the potential interference from the rear rotor could be suppressed with the increase of the blade row distance from $L=$ $10 \mathrm{~mm}$ to $L=30 \mathrm{~mm}$.

The pressure fluctuations at the LE of the rear rotor obtained by the numerical analysis are shown in Figure 8. The flow rate, vertical axis and horizontal axis are the same in Figure 7. Because the pressure in Figure 8 was phase locked the rear rotor rotation, the wake and potential interference from the front rotor became clear if the unsteady pressure fluctuations from the rear rotor were small. The periodic pressure fluctuations with four peaks corresponding to the front rotor blade number $Z_{F}=4$ were generated for the blade row distance $L=10 \mathrm{~mm}$ and $L=30 \mathrm{~mm}$ in Figure 8. The pressure fluctuations $\Delta P_{s}$ at the LE of the rear rotor were larger than those at the TE of the front rotor. The pressure fluctuations $\Delta P_{s}$ at the LE of the rear rotor near the shroud at $r / r_{c}=0.98$ were significantly large compared to those at other radial positions. These large pressure fluctuations near the shroud would be related to the flow condition at the rear rotor inlet. When the pressure fluctuations $\Delta P_{s}$ of the front and rear rotors were compared, the pressure fluctuations $\Delta P_{s}$ of the rear rotor larger than that of front rotor as shown in Figure 7 and Figure 8. The variation of the blade loading of

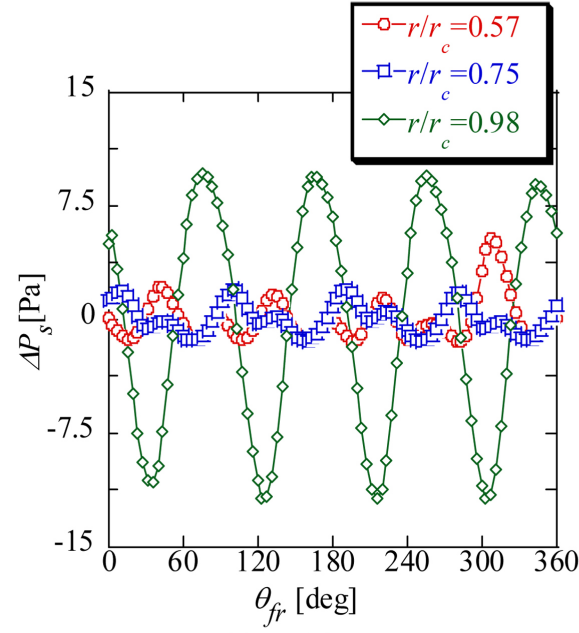

(a) $L=10 \mathrm{~mm}$

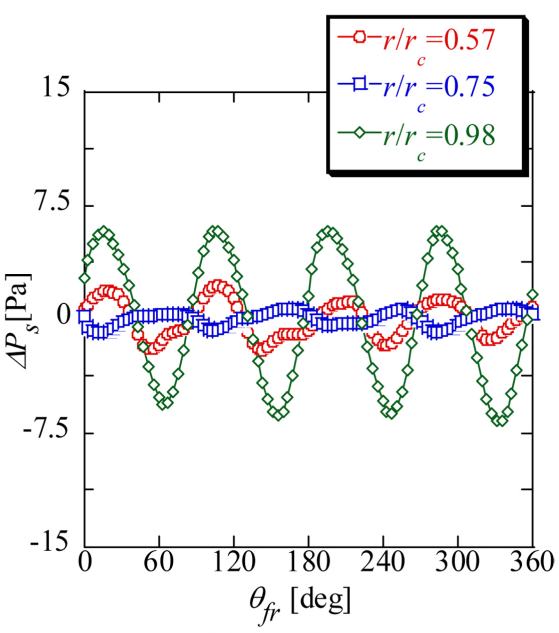

(b) $L=30 \mathrm{~mm}$

Figure 8. Pressure fluctuations at LE of rear rotor. 
the rear rotor with the rotor rotation caused by the pressure fluctuations in Figure 8 would be larger than that of the front rotor. Therefore, it is important to consider the influence of the wake and potential interferences especially on the rear rotor for the stable operation of the contra-rotating small sized fan. On the other hand, the wake and potential interference from the front rotor could be suppressed with the increase of the blade row distance from $L=10 \mathrm{~mm}$ to $L=30$ $\mathrm{mm}$ as shown in Figure 7 and Figure 8.

In order to investigate the large pressure fluctuations near the shroud of the rear rotor, the meridional velocity vectors and vorticity at the design flow rate for $L=10 \mathrm{~mm}$ and $L=30 \mathrm{~mm}$ is shown in Figure 9 and Figure 10 respectively. The direction of the main flow is from left side to right sight of the paper and the rotational direction of the front rotor is from the front side to back side of the paper and vice versa for the rear rotor. The flow rate is the design flow rate. Crock wise direction of the vorticity is positive and anti-crock wise direction is negative. Regardless of the magnitude of the vectors, the length of the vector is the same. So the velocity vectors show only the direction of the velocity. The vortex of leakage flow from the front rotor tip clearance is observed in Figure 9 and Figure 10 as the blue region for both $L=10 \mathrm{~mm}$ and $L=30 \mathrm{~mm}$ near the shroud of the casing. The strength of vorticity was kept up to the entrance of the rear rotor for $L=10 \mathrm{~mm}$. Then, the vortex from the front rotor joined with the vortex of the rear rotor; the leakage flow from the front rotor tip clearance joined with the low pressure region associated with the leakage flow of the rear rotor tip clearance. On the other hand, the vorticity of the front rotor became weak near the inlet of the rear rotor for $L=30 \mathrm{~mm}$. These flow conditions related to the leakage flow from the front rotor tip significantly influenced on the pressure fluctuations of the rear rotor near the shroud. The pressure distributions for $L=10 \mathrm{~mm}$ and $L=30 \mathrm{~mm}$ near the shroud at $r / r_{c}=0.98$ are shown in Figure 11 and Figure 12. The flow rate is the design flow rate. The leakage flow from the front rotor tip clearance flowed down and when it reached the suction surface of the rear rotor, the pressure distribution on the suction surface of the rear rotor was fluctuated for $L=10 \mathrm{~mm}$. It was found in Figure 12 that the influence of the leakage flow became weak for $L=30 \mathrm{~mm}$ and pressure fluctuation on the suction surface of the rear rotor decreased.

The pressure fluctuations of the rear rotor were large. Then, the attack angle variations with the rotor rotation at the design flow rate $Q_{d}$ were investigated by the numerical analysis. Figure 13 shows the attack angle variations of the rear rotor with the rotors rotation. The vertical axis is attack angle and the horizontal axis is the relative angle of the front and rear rotors $\theta_{f r}$ The attack angle variations of the rear rotor for $L=10 \mathrm{~mm}$ were larger than those for $L=30 \mathrm{~mm}$. It was considered that the wake from the front rotor and pressure distribution around the front rotor would influence on the attack angle of the rear rotor. Especially at $r / r_{c}=0.98$, the leakage flow from the front rotor could induce the attack angle variations in Figure 13. The pressure fluctuations and attack angle 

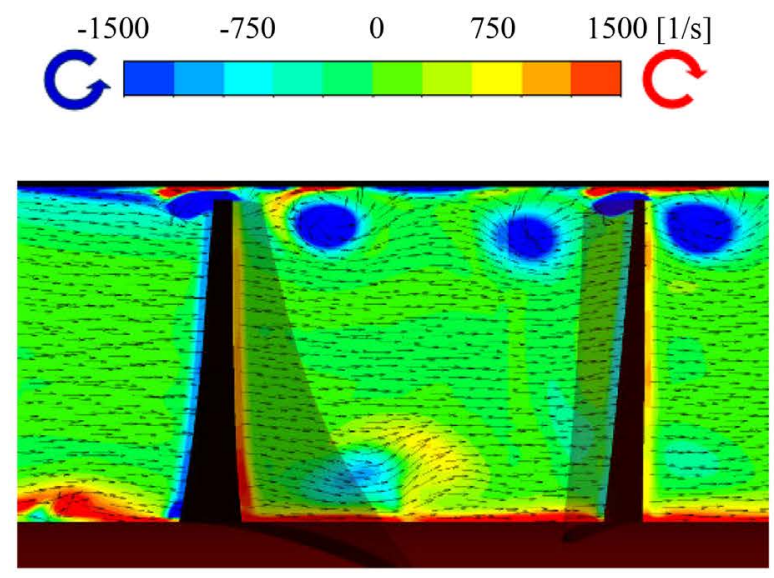

(a) $\theta_{f r}=20^{\circ}$

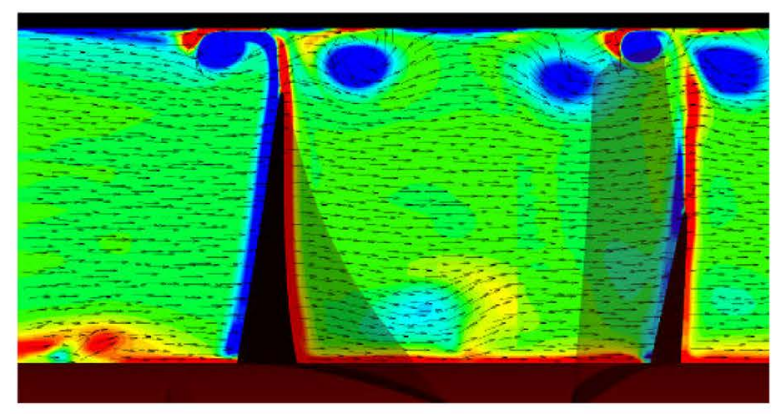

(b) $\theta_{f r}=40^{\circ}$

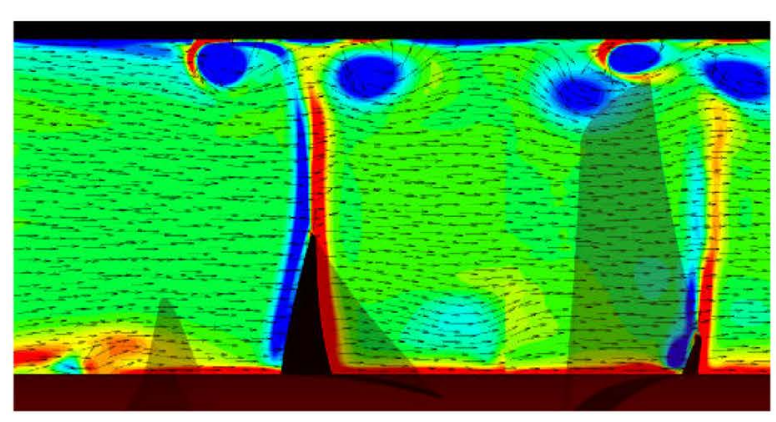

(c) $\theta_{f t}=60^{\circ}$

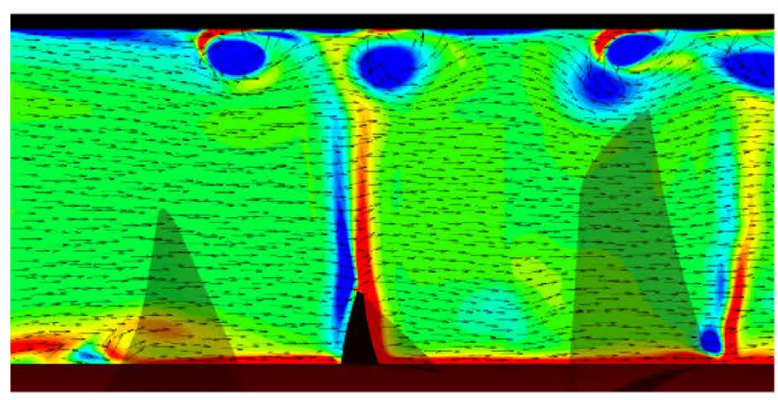

(d) $\theta_{\mathrm{fr}}=80^{\circ}$

Figure 9. Meridional velocity vectors and vorticity at $Q_{d}$ for $L=10 \mathrm{~mm}$. 


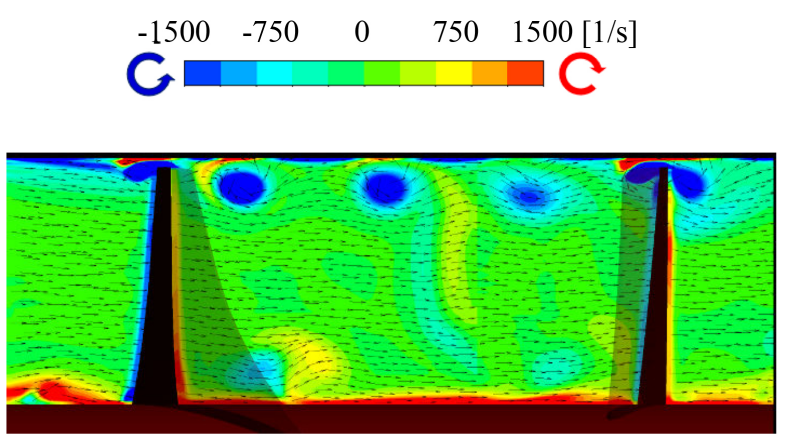

(a) $\theta_{f r}=20^{\circ}$

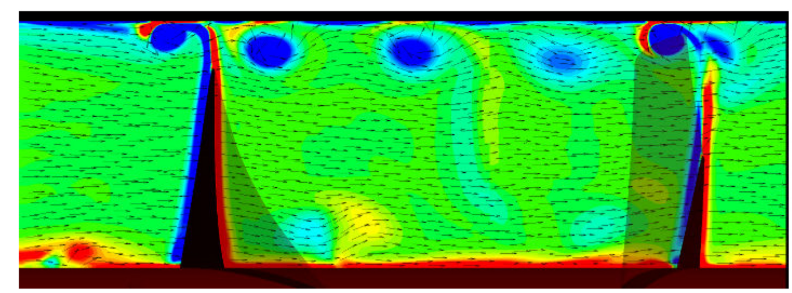

(b) $\theta_{f r}=40^{\circ}$

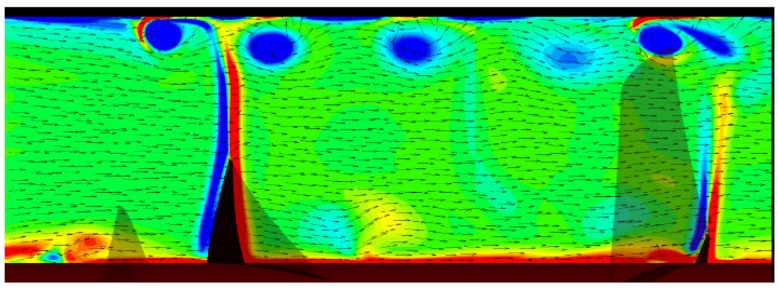

(c) $\theta_{f r}=60^{\circ}$

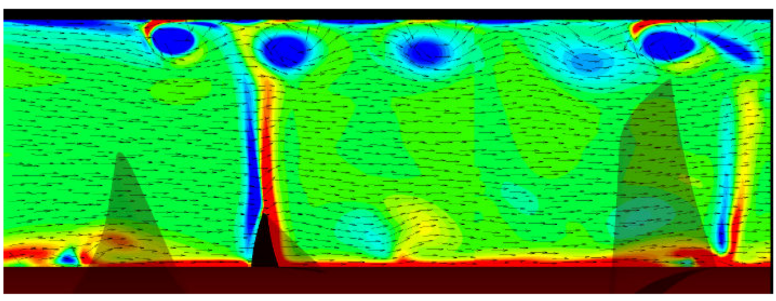

(d) $\theta_{f r}=80^{\circ}$

Figure 10. Meridional velocity vectors and vorticity at $Q_{d}$ for $L=30 \mathrm{~mm}$.

variations were suppressed for the blade row distance $L=30 \mathrm{~mm}$. Therefore, the blade row distance $L=30 \mathrm{~mm}$ would be appropriate blade row distance because the performance decrease with the increase of the blade row distance was small by $L=30 \mathrm{~mm}$ and the wake, potential interference and leakage flow from the front rotor could be suppressed effectively for $L=30 \mathrm{~mm}$.

\section{Conclusions}

The performance test of the contra-rotating small-sized axial fan was conducted under the condition of different blade row distance. Then, the wake and potential interference between the front and rear rotors were investigated at the design 


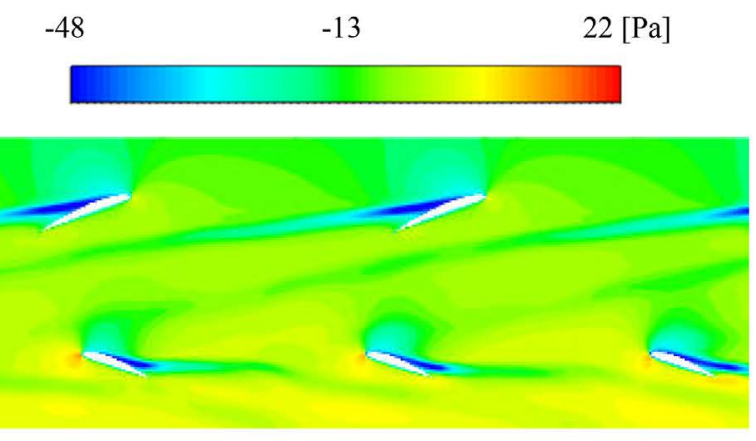

(a) $\theta_{j r}=20^{\circ}$

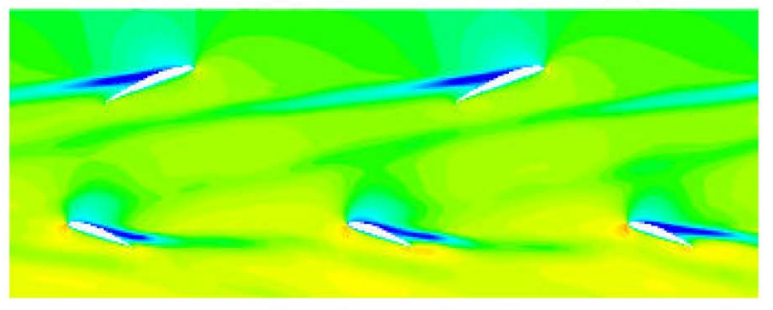

(b) $\theta_{j i}=40^{\circ}$

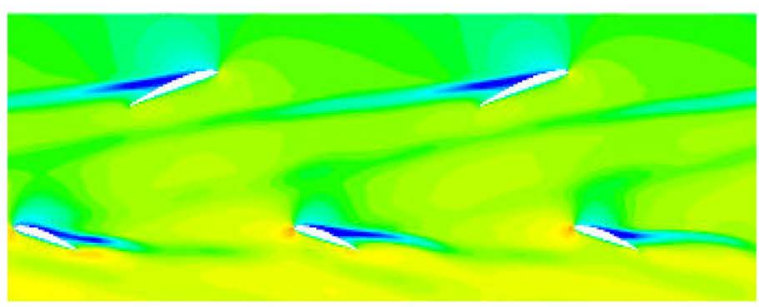

(c) $\theta_{j i}=60^{\circ}$

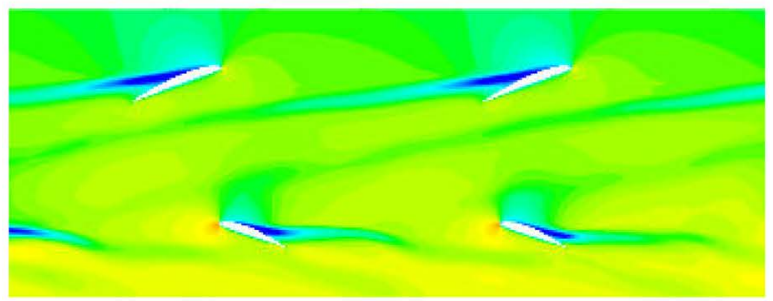

(d) $\theta_{f i}=80^{\circ}$

Figure 11. Pressure distribution at $Q_{d}$ for $L=10 \mathrm{~mm}\left(r / r_{c}=\right.$ $0.98)$.

flow rate $Q=0.016 \mathrm{~m}^{3} / \mathrm{s}$ with the unsteady numerical analysis. As a result, following concluding remarks could be obtained:

1) The difference of the fan static pressure between $L=10 \mathrm{~mm}$ and $L=30 \mathrm{~mm}$ was $P_{s}=0.02 \mathrm{~Pa}$ (Exp.) at the design flow rate $Q_{d}=0.016 \mathrm{~m}^{3} / \mathrm{s}$. The maximum static pressure efficiency was $\eta=58.0 \%$ for $L=10 \mathrm{~mm}$ and $\eta=57.0 \%$ for $L=30$ $\mathrm{mm}$. The influences of the blade row distance in the range of $L=10-30 \mathrm{~mm}$ on the fan static pressure and static pressure efficiency were small.

2) The strength of vorticity associated with the leakage flow from the front 


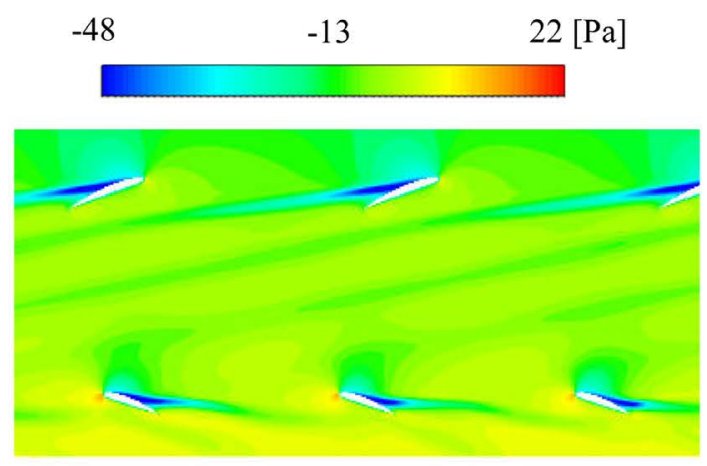

(a) $\theta_{f r}=20^{\circ}$

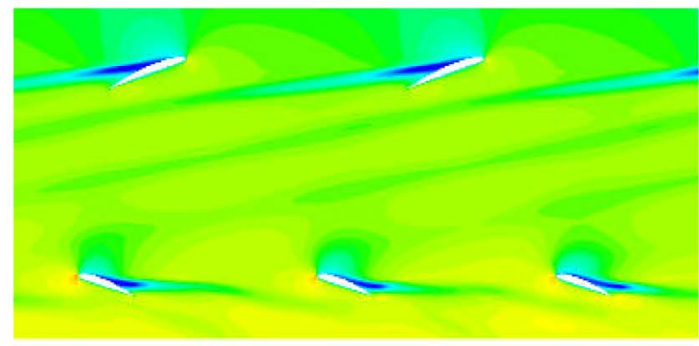

(b) $\theta_{f r}=40^{\circ}$

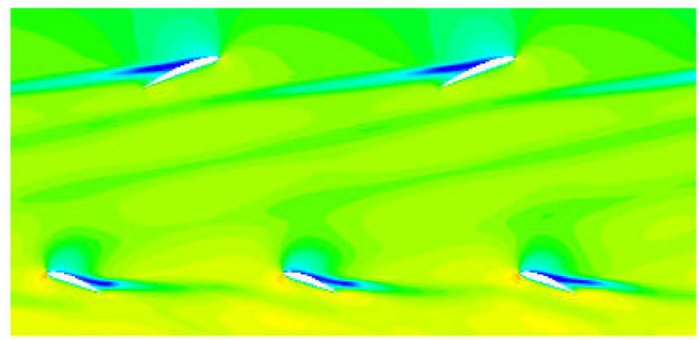

(c) $\theta_{f i}=60^{\circ}$

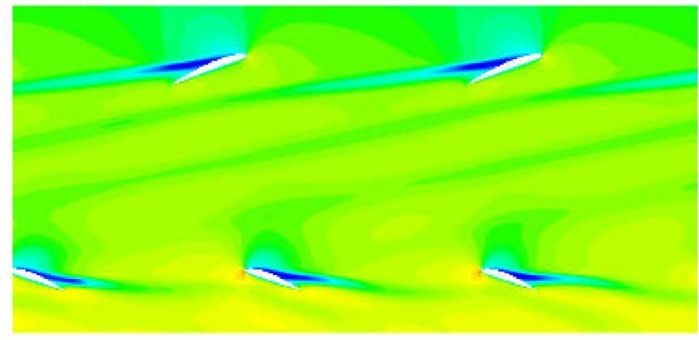

(d) $\theta_{f r}=80^{\circ}$

Figure 12. Pressure distribution at $Q_{d}$ for $L=30 \mathrm{~mm}$ $\left(r / r_{c}=0.98\right)$.

rotor was kept up to the entrance of the rear rotor for $L=10 \mathrm{~mm}$. Then, the leakage flow from the front rotor tip clearance joined with the low pressure region associated with the leakage flow of the rear rotor tip clearance. On the other hand, the vorticity of the front rotor tip clearance became weak near the inlet of the rear rotor for $L=30 \mathrm{~mm}$.

3) The wake from the front rotor and pressure distribution around the front rotor would influence on the attack angle of the rear rotor. Especially at $r / r_{c}=$ 


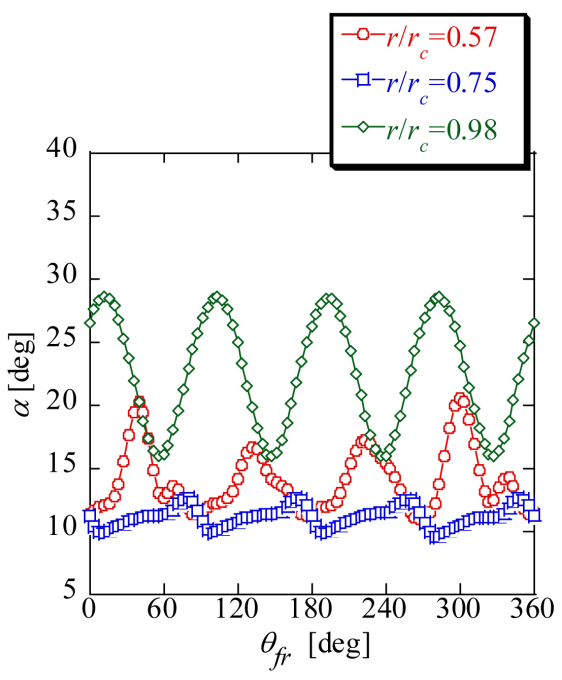

(a) $L=10 \mathrm{~mm}$

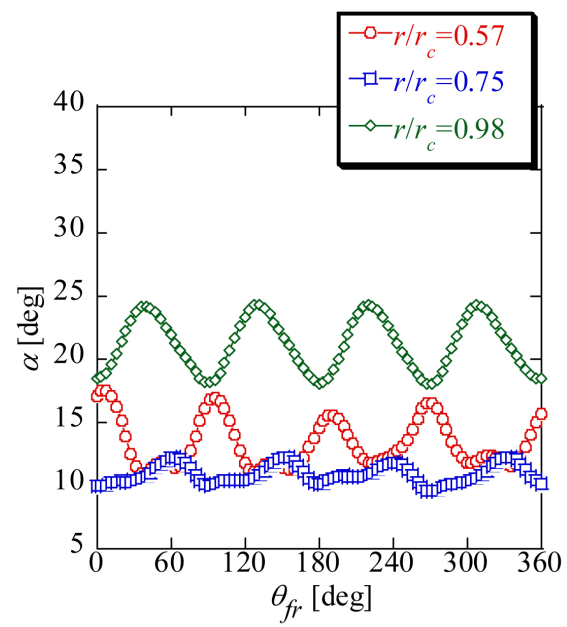

(b) $L=30 \mathrm{~mm}$

Figure 13. Attack angle variations of rear rotor with rotation.

0.98 , the leakage flow from the front rotor tip clearance could induce the attack angle variations.

4) The pressure fluctuations and attack angle variations were suppressed for the blade row distance $L=30 \mathrm{~mm}$. Therefore, the blade row distance $L=30 \mathrm{~mm}$ would be appropriate blade row distance because the performance decrease with the increase of the blade row distance was small by $L=30 \mathrm{~mm}$ and the wake, potential interference and leakage flow from the front rotor could be suppressed effectively for $L=30 \mathrm{~mm}$.

\section{Acknowledgements}

The authors wish to show our special thanks to the supports by the Komiya research aid, the project research aid from Tokushima University and Japan Science and Technology Agency. 


\section{References}

[1] Hata, T. and Nakamoto, S. (2010) Energy Saving Service for Data Centers. Journal of the Japan Society for Precision Engineering, 76, 272-275. (In Japanese) https://doi.org/10.2493/jjspe.76.272

[2] Furukawa, A., Shigemitsu, T. and Watanabe, S. (2007) Performance Test and Flow Measurement of Contra-Rotating Axial Flow Pump. Journal of Thermal Science, 16, 7-13. https://doi.org/10.1007/s11630-007-0007-4

[3] Furukawa, A., Cao, Y., Okuma, K. and Watanabe, S. (2000) Experimental Study of Pump Characteristics of Contra-Rotating Axial Flow Pump. Proceedings of the 2 nd International Symposium on Fluid Machinery and Fluid Engineering, Beijing, 67, 245-252.

[4] Nouri, H., Ravelet, F., Bakir, F., Sarraf, C. and Rey, R. (2012) Design and Experimental Validation of a Ducted Counter-Rotating Axial-Flow Fans System. Journal of Fluids Engineering, 134, 104504. https://doi.org/10.1115/1.4007591

[5] Shigemitsu, T., Furukawa, A., Okuma, K. and Watanabe, S. (2002) Experimental Study on Rear Rotor Design in Contra-Rotating Axial Flow Pump. Proceedings of 5th JSME/ KSME Fluids Engineering Conference, Nagoya, 17-21 November, 2002, 1453-1548.

[6] Wang, C. and Huang, L. (2014) Passive Noise Reduction for a Contrarotating Fan. Journal of Turbomachinery, 137, 031007. https://doi.org/10.1115/1.4028357

[7] Sanders, A.J., Papalia, J. and Fleeter, S. (2002) Multi-Blade Row Interactions in a Transonic Axial Compressor: Part I-Stator Particle Image Velocimetry (PIV) Investigation. Journal of Turbomachinery, 124, 10-18.

https://doi.org/10.1115/1.1411973

[8] Nouri, H., Danlos, A., Ravelet, F., Bakir, F. and Sarraf, C. (2013) Experimental Study of the Instationary Flow between Two Ducted Counter-Rotating Rotors. Journal of Engineering for Gas Turbines and Power, 135, 022601. https://doi.org/10.1115/1.4007756

[9] Shigemitsu, T., Fukutomi, J. and Okabe, Y. (2010) Performance and Flow Condition of Small-Sized Axial Fan and Adoption of Contra-Rotating Rotors. Journal of Thermal Science, 19, 1-6. https://doi.org/10.1007/s11630-010-0001-0

[10] Ito, T., Minorikawa, G., Nagamatsu, A. and Suzuki, S. (2006) Experimental Research for Performance and Noise of Small Axial Flow Fan (Influence of Parameter of Blade). Transactions of the JSME, 72, 670-667. (In Japanese) https://doi.org/10.1299/kikaib.72.670

[11] Shigemitsu, T., Fukutomi, J. and Shimizu H. (2012) Influence of Blade Row Distance on Performance and Flow Condition of Contra-Rotating Small-Sized Axial Fan. International Journal of Fluid Machinery and Systems, 5, 161-167. https://doi.org/10.5293/IJFMS.2012.5.4.161 
Submit or recommend next manuscript to SCIRP and we will provide best service for you:

Accepting pre-submission inquiries through Email, Facebook, LinkedIn, Twitter, etc. A wide selection of journals (inclusive of 9 subjects, more than 200 journals)

Providing 24-hour high-quality service

User-friendly online submission system

Fair and swift peer-review system

Efficient typesetting and proofreading procedure

Display of the result of downloads and visits, as well as the number of cited articles Maximum dissemination of your research work

Submit your manuscript at: http://papersubmission.scirp.org/

Or contact ojfd@scirp.org 